\title{
Caracterização paleoambiental a partir de microfácies carbonáticas da Formação Itaituba (Pensilvaniano Inferior da Bacia do Amazonas), no município de Itaituba (PA)
}

\author{
Katy Marilym de Matos NEVES \& Valquíria Porfírio BARBOSA
}

Programa de Pós-graduação em Geociências, Universidade Federal do Amazonas. Av. General Rodrigo Octavio Jordão Ramos, 1200, CEP 69067-005, Manaus, AM, Brasil (katy.matosneves@gmail.com e pbvalquiria@gmail.com)

\begin{abstract}
Resumo. Visando a interpretação e a inferência dos paleoambientes de duas sucessões carbonática pertencente à Formação Itaituba (Pensilvaniano da Bacia do Amazonas), que aflora às margens do Rio Tapajós, SW do Estado do Pará, estudos petrográficos voltados à caracterização e identificação de microfáceis sedimentares foram realizados a partir da análise de 50 seções delgadas. A análise petrográfica foi desenvolvida de acordo com a metodologia padrão para estudos desta natureza, envolvendo, essencialmente, a classificação das rochas carbonáticas, a caracterização e a individualização de microfácies. Como resultado destas análises foram identificadas nove microfácies: Mudstone com evaporitos (Me), Wackestone com terrígenos (Wt), Wackestone com quartzo autigênico e fitoclastos (Wqf), Wackestone com braquiópodes e crinóides ( $\mathrm{Wbc}$ ), Packstone com braquiópodes (Pb), Grainstone com braquiópodes (Gb), Grainstone com fusulinídeos (Gf), Grainstone com aglutinantes (Ga) e Boundstone com intraclastos (Bi). Destas microfácies, foram distinguidas quatro microbiofácies, baseadas nos trends e análise dos bioclastos, e cinco associações de grãos não-esqueletais, fundamentadas no significado sedimentológico destes grãos. A partir disto, foram interpretadas cinco associações de microfácies (AMF) representativas de sistemas deposicionais distintos: AMF-01) sabkha, AMF- 02) planície de maré, AMF-03) laguna, AMF-04) canais de maré e AMF05) barras bioclásticas. Estas associações de microfácies indicam um modelo deposicional de plataforma carbonática em rampa, com o desenvolvimento de um sistema deposicional marinho raso, dominado por sedimentação carbonática, influenciado por maré, sob regime climático dominante de clima semiárido e temperatura da massa d'água variando de temperada a quente. Palavras-chave. Petrografia, microfácies, paleoambientes, Formação Itaituba
\end{abstract}

\begin{abstract}
PALEOENVIRONMENTAL CHARACTERIZATION FROM THE CARBONATE MICROFACIES OF THE ITAITUBA Formation (LOWER PENSILVANIANO OF THE AMAZONAS BASIN), IN THE MUNICIPALITY OF ITAITUBA (PA). Aiming at the interpretation and inference of the paleoenvironments of two carbonate succession belonging to the Itaituba Formation (Pennsylvanian of the Amazonas Basin), which appears on the banks of the Tapajós River, SW of the state of Pará, petrographic studies focused at the characterization and identification of sedimentary microfacies were performed from the analysis of 50 thin sections. The petrographic analysis was developed according to the standard methodology for studies of this nature, essentially involving the classification of carbonate rocks, the characterization and individualization of microfacies. As a result of these analyzes, nine microfacies were identified: Mudstone with evaporites (Me), Wackestone with terrígenos (Wt), Wackestone with autigenic quartz and fitoclasts (Wqf), Wackestone with brachiopods and crinoids (Wbc), Packstone with brachiopods (Pb), Grainstone (Gb), Grainstone with fusulinids (Gf), Grainstone with binders (Ga) and Boundstone with intraclasts (Bi). From these microfacies, four microbiofacies, based on the bioclastic trends and analysis, and five associations of non-skeletal grains, based on the meaning of these grains. From this, five associations of microfacies (AMF) representative of different depositional systems were interpreted: AMF-01) sabkha, AMF-02) tidal plain, AMF-03) lagoon, AMF-04) tidal channels and AMF-05) bioclastic bars. These associations of microfacies indicate a depositional carbonaceous platform model in ramp, with the development of a shallow marine depositional system, dominated by carbonate sedimentation, influenced by tide, under the dominant regime of semiarid climatic and temperature of the water mass varying from temperate to hot.
\end{abstract}

Keywords. Petrography, microfacies, paleoenvironments, Itaituba Formation. 


\section{Introdução}

Em petrografia sedimentar, a identificação e a caracterização de microfácies é sem dúvida um dos atributos fundamentais ao estudo e à inferência de paleoambientes deposicionais, pois além de sua aplicação natural para o posicionamento estratigráfico de sucessões sedimentares, também constitui uma ferramenta potencial ao reconhecimento de eventos e processos relacionados à evolução sedimentar destas sucessões de rochas.

Por sua vez, o reconhecimento destes eventos consiste em uma etapa fundamental à caracterização e à elucidação da história deposicional de qualquer unidade ou bacia sedimentar, sendo, portanto, um atributo essencial para a correlação de estratos e para a construção de arcabouços estratigráficos.

Nesse contexto, a identificação de associações de microfácies representa uma outra etapa fundamental para o desenvolvimento de modelos de sedimentação, particularmente no que se refere a sequências carbonáticas. Isso porquê, de acordo com Flügel (2010), estas associações correspondem a critérios representativos de parâmetros ou conjuntos de parâmetros ambientais específicos (representados por conjuntos de microfácies), cuja evolução está ligada a configurações deposicionais específicas. Assim, a caracterização das diferentes associações de microfácies requer o desenvolvimento de análises qualitativas e quantitativas dos constituintes das microfácies que os compõem.

Em outras palavras, a utilização de associações de microfácies como um proxy em inferências paleoambientais envolve a identificação e a compreensão de processos sedimentares e de parâmetros bióticos eabióticos do meio (análise qualitativa dos constituintes das rochas), as quais devem ser suportadas pelo estabelecimento de padrões de distribuição e frequência de constituintes selecionados (análises semi-quantitativa ou quantitativa dos constituintes das rochas).

No que se refere aos constituintes das rochas carbonáticas, Flügel (2010) afırma que os fósseis são um dos proxies mais significativos para a determinação de condições paleoambientais, graças à sensibilidade natural dos seres vivos às variações de parâmetros como temperatura, salinidade, luminosidade, balanço de $\mathrm{CO}_{2}$, profundidade da lâmina d'água, natureza do regime de correntes locais, turbidez e natureza do substrato.

Por sua vez, grãos carbonáticos nãoesqueletais também são apontados por aquele autor como proxies potenciais, pois muitos processos bióticos que dependem de parâmetros ambientais físicos e químicos (e.g., níveis de energia da água e taxas de sedimentação) podem controlar sua formação.

No caso de constituintes não-carbonáticos, grande parte das informações que podem ser obtidas reflete tanto processos sedimentares e diagenéticos (processos erosivos, influxo de terrígenos, etc.) quanto eventos de menor ou maior amplitude na bacia de sedimentação (alterações climáticas, variações do nível relativo do mar, etc.).

Por isso, em estudos petrográficos destinados à interpretação paleoambiental, a qualificação e a quantificação dos padrões de frequência e distribuição de bioclastos, grãos carbonáticos não-esqueletais e grãos nãocarbonáticos é de suma importância e podem fornecer um precioso auxílio na identificação e caracterização das associações de microfácies e, consequentemente, na individualização de configurações deposicionais específicas.

Assim, considerando os objetivos gerais deste trabalho, os quais visam a interpretação paleoambiental de duas sucessões de rochas carbonáticas pertencentes à Formação Itaituba (Grupo Tapajós, Pensilvaniano da Bacia do Amazonas), além dos métodos tradicionalmente empregados em estudos petrográficos destinados a identificação e caracterização de microfácies, foram desenvolvidas análises qualitativas e quantitativas de diferentes classes de grãos de rochas carbonáticas (bioclastos, grãos carbonáticos não esqueletais e grãos nãocarbonáticos).

A realização destas análises e a seleção destes constituintes tiveram como finalidade identificar tipos de grãos e/ou associações de grãos que pudessem ser empregados como 
elementos na identificação de parâmetros ambientais específicos (salinidade, oxigenação, temperatura, luminosidade, regime climático, etc.).

\section{2 Área, materiais e métodos}

\section{1 Localização da área}

A área de estudo localiza-se no Munícipio de Itaituba, sudoeste do Estado do Pará e corresponde a duas frentes de lavra de uma mina de calcário de propriedade da Mineradora CALREIS (409'26" S 5545'51" W), situada na margem direita do Rio Tapajós, à jusante em direção ao Munícipio de Santarém, em uma região que, geologicamente, corresponde à borda sul da Bacia do Amazonas (Fig. 1). Foi visitada em novembro de 2012 em trabalhos de campo, durante os quais foram levantados quatro perfis estratigráficos, que compõem um pacote sedimentar de aproximadamente $16 \mathrm{~m}$ de espessura (Fig. 2), sendo os perfis A, B e C relativos a afloramentos pertencentes à primeira frente de lavra e o perfil D à segunda.

\subsection{Aspectos geológicos}

A Bacia do Amazonas é uma sinéclise intracratônica paleozoica, gerada por uma lenta subsidência durante o transcurso de vários períodos geológicos, do Ordoviciano ao Cenozoico (Hasui et al., 2012). Localiza-se na porção setentrional da Plataforma Sul Americana, ocupando uma área total de 606.000 km² (CPRM, 2010) e espessura aproximada de $5.000 \mathrm{~m}$ no depocentro (Milani \& Thomaz Filho, 2000).

De acordo com Cunha et al. (2007), o preenchimento sedimentar da bacia é composto por duas megassequências de primeira ordem: Paleozoica e Mesozoico-Cenozoica, sendo a primeira dividida em quatro sequências de segunda ordem: Ordovicio-Devoniana, DevonoTournaisiana, Neoviseana e PensilvanianoPermiana. De acordo com Cunha (2000), a sedimentação desta última sequência, objeto deste estudo, é constituída pelo Grupo Tapajós, composto pelas formações Monte Alegre, Itaituba, Nova Olinda e Andirá e é interpretada como representativa de um ciclo transgressivoregressivo ocorrido no Pensilvaniano-Permiano.

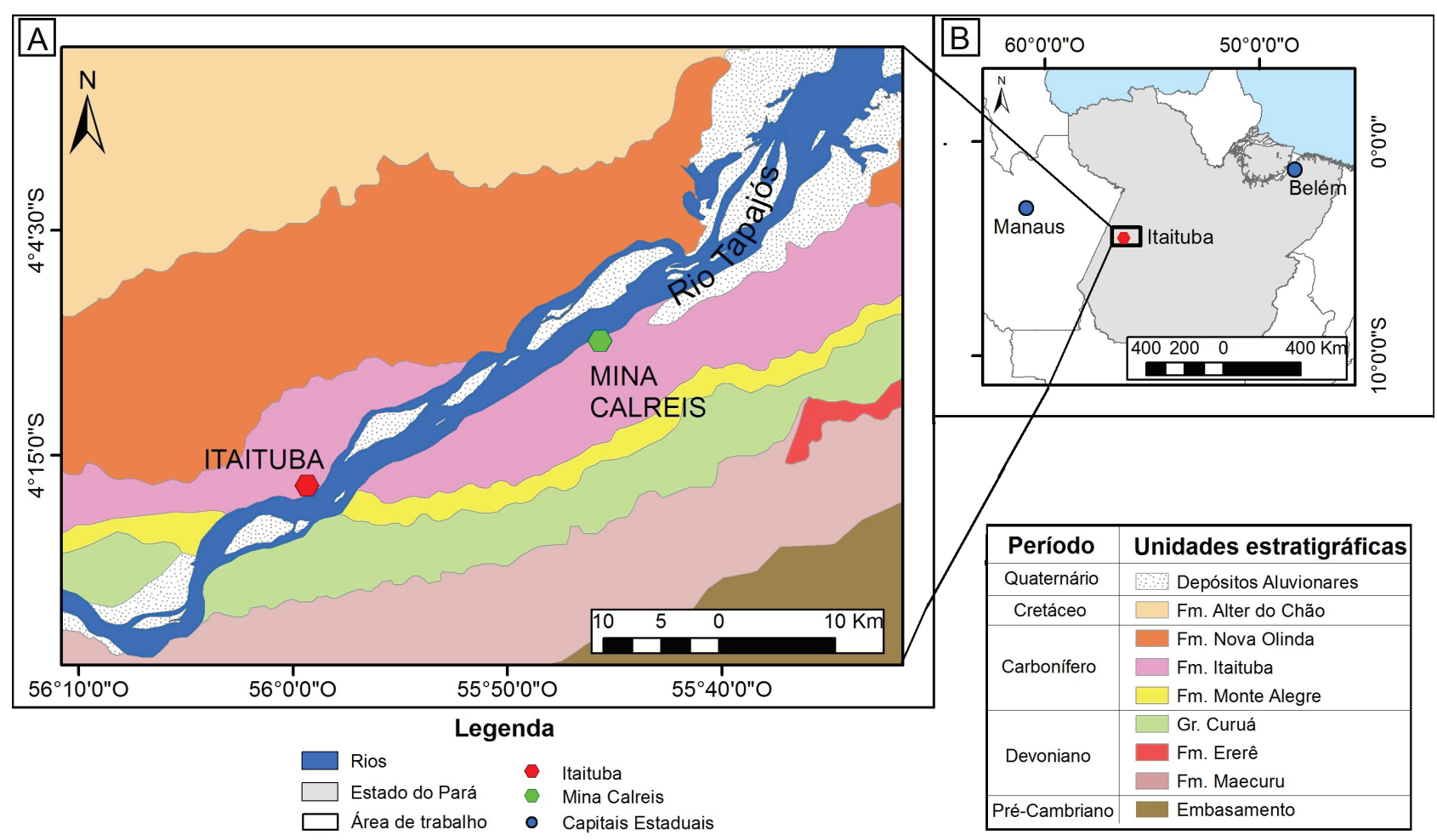

Figura 1. Área de estudo. A) Mapa geológico com a distribuição das unidades estratigráficas na região do município de Itaituba-PA; B) Localização da área de estudo (Fonte: CPRM, 2016).

Figure 1. Area of study. A) Geological map with the distribution of stratigraphic units in the region of Itaituba-PA; B) Location of the study area (Source: CPRM, 2016). 


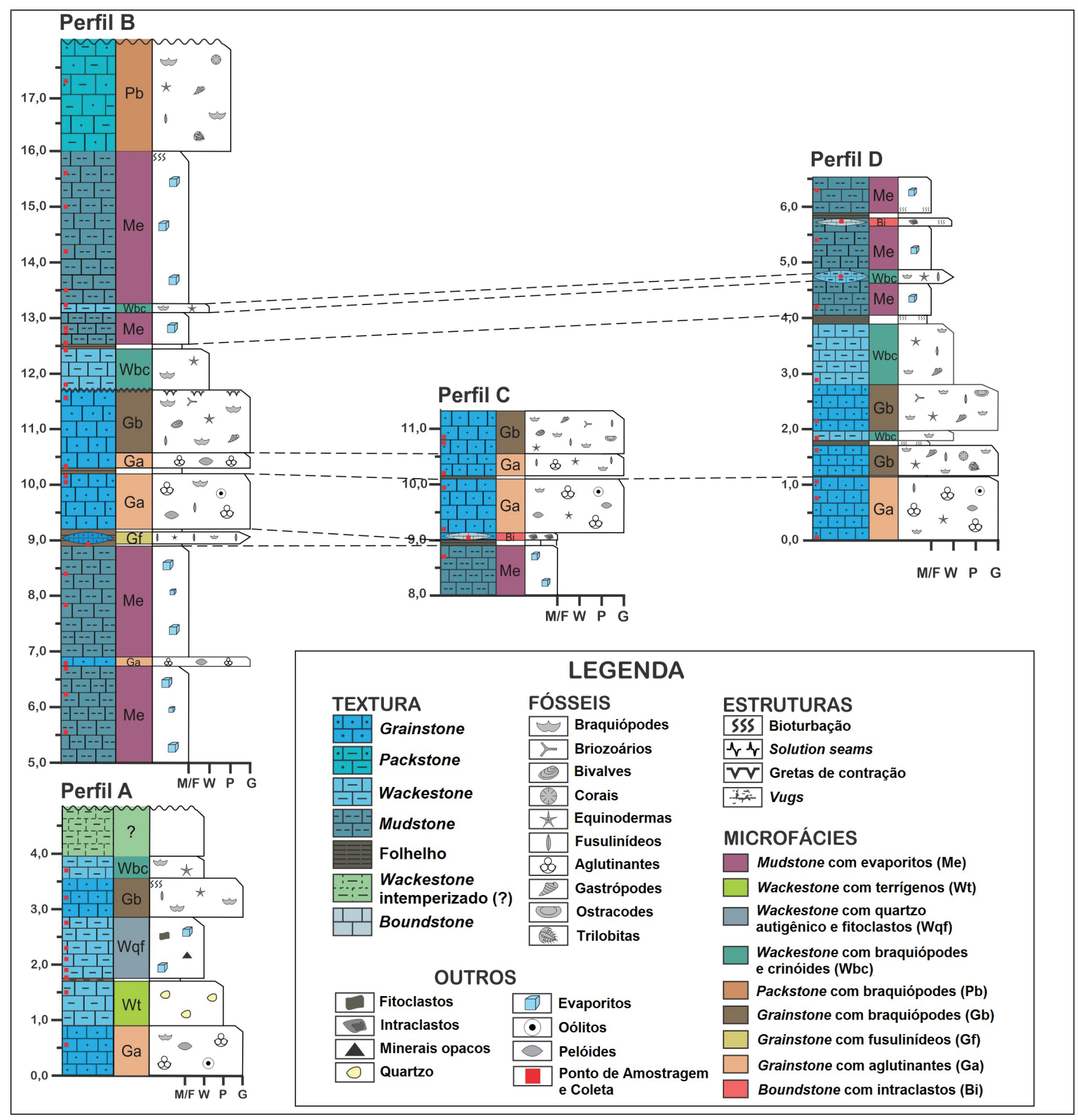

Figura 2. Perfis estratigráficos de sucessão carbonática da Formação Itaituba (Grupo Tapajós, Pensilvaniano da Bacia do Amazonas), referentes a duas frentes de lavra da Mineradora CALREIS, localizada no município de Itaituba-PA e que compõem um pacote sedimentar de aproximadamente $16 \mathrm{~m}$ de espessura, sendo os perfis $\mathrm{A}$, $\mathrm{B}$ e $\mathrm{C}$ afloramentos pertencentes a primeira frente de lavra e o perfil D a segunda.

Figure 2. Stratigraphic profiles of carbonate succession of the Itaituba Formation (Tapajós Group, Pensilvaniano da Amazonas Basin), referring to two mining fronts of the CALREIS Mining, located in the municipality of Itaituba-PA, which compose a sedimentary package approximately $16 \mathrm{~m}$ thick, the profiles $A, B$ and $C$ being outcrops belonging to one mining front and the profile $D$ the second.

Entre as unidades litoestratigráficas que compõem o grupo Tapajós, a Formação Itaituba destaca-se, entre outros aspectos pela representativa espessura do pacote carbonático e por seu rico conteúdo fossilífero. Esta unidade possui ampla distribuição na Bacia do Amazonas ocupando cerca de $420 \mathrm{~m}$ de espessura na região de depocentro da bacia (Caputo, 1984). É composta por inúmeras sequências carbonáticoevaporíticas, intercaladas por delgadas camadas siliciclásticas que compõem um padrão de sedimentação cíclica constituída por vários litotipos como folhelhos, carbonatos e evaporitos, que foram associados a ambiente lagunar e marinho raso/inframaré de idade pensilvaniana (Cunha et al., 2007). 
Neste contexto, as rochas carbonáticas pertencentes a esta formação são interpretadas como evidências do estabelecimento de condições francamente marinhas na Bacia do Amazonas, marcado pela sedimentação de diversos litotipos carbonáticos (e. g., mudstones, wackestones, packstones, e grainstones) e por um rico conteúdo fossilífero composto por táxons exclusivamente marinhos (e. g., foraminíferos bentônicos, conodontes, escolecodontes, ostracodes, briozoários, corais, gastropodes, bivalves, braquiópodes e trilobitas, entre outros) (Scomazzon \& Lemos, 2005; Nascimento et al., 2010; Scomazzon et al., 2016; Moutinho et al., 2016a).

\subsection{Materiais e métodos}

Foram utilizadas 50 lâminas delgadas de amostras de rochas carbonáticas provenientes dos quatro afloramentos estudados, as quais foram laminadas pelo Laboratório de Sedimentologia e Estratigrafia da Petrobrás, Unidade de Manaus (UO/AM), armazenadas na Universidade Federal do Amazonas.

A análise petrográfica foi desenvolvida com o auxílio de um microscópio ótico petrográfico Olympus modelo BX51 com objetivas de 5x, 10x, 20x, 40x pertencente ao Departamento de Geociências da Universidade Federal do Amazonas (DEGEO - UFAM). Visando complementar a caracterização petrográfica das rochas, em algumas lâminas petrográficas foi também empregada Microscopia Eletrônica de Varredura (MEV). O aparelho utilizado foi um MEV QUANTA 250 pertencente ao DEGEO - UFAM e a metodologia empregada envolveu, essencialmente, a metalização com ouro e a subsequente captura de imagens de raios $X$ e de espalhamento de elétrons com resolução nanométrica.

Durante a análise petrográfica foram desenvolvidas quatro etapas fundamentais: descrição das amostras, análise qualitativa e quantitativa dos grãos, identificação de estruturas e análise semi-quantitativa da razão matriz/grãos. A partir do desenvolvimento destas etapas, foram realizadas análises e inferências destinadas a: classificação litológica das rochas carbonáticas, caracterização e individualização de microfácies, inferência do índice de energia do ambiente e levantamento paleoecológico dos fósseis e do significado sedimentar dos grãos não-esqueletais.

A classificação das rochas carbonáticas seguiu o modelo de Dunham (1962); a caracterização e a individualização de microfácies foi feita segundo a proposta de Flügel (2010); a nomenclatura e a codificação das microfácies seguiram a proposta de fácies de Miall (1977). O estudo paleoecológico foi feito a partir de um criterioso levantamento bibliográfico visando a observação das preferências dos principais táxons identificados no intervalo de tempo analisado (Carbonífero).

0 entendimento do significado sedimentológico dos grãos não-esqueletais também foi realizado a partir de pesquisas bibliográficas destinadas ao levantamento de relações com parâmetros físicos e químicos do ambiente de sedimentação apontados por estes clastos. A inferência do índice de energia do ambiente seguiu a proposta de classificação de Plumley et al. (1962, apud Flügel, 2010).

Por fim, através da integração dos resultados obtidos destas análises foram caracterizadas e identificadas cinco associações de microfácies, de acordo com os critérios considerados por Flügel (2010).

\section{Resultados}

\subsection{Microfácies}

Foram caracterizadas e individualizadas nove microfácies, as quais são descritas e ilustradas a seguir (Figs. 3 e 4).

Mudstone com evaporitos (Me) (Fig. 3AC): caracterizada por cerca de $93 \%$ de matriz

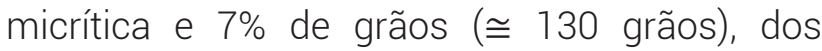
quais 95\% são representados por clastos nãoesqueletais e $5 \%$ por bioclastos. Os clastos nãoesqueletais são constituídos por halita (80\%), quartzo autigênico (14\%) e por anidrita (1\%), e os bioclastos por restos e fragmentos esqueletais de braquiópodes (2\%), fusulinídeos (1\%), crinóides (1\%) e gastrópodes, miliolídeos, corais Rugosa coloniais e bivalves, os quais somados totalizam 

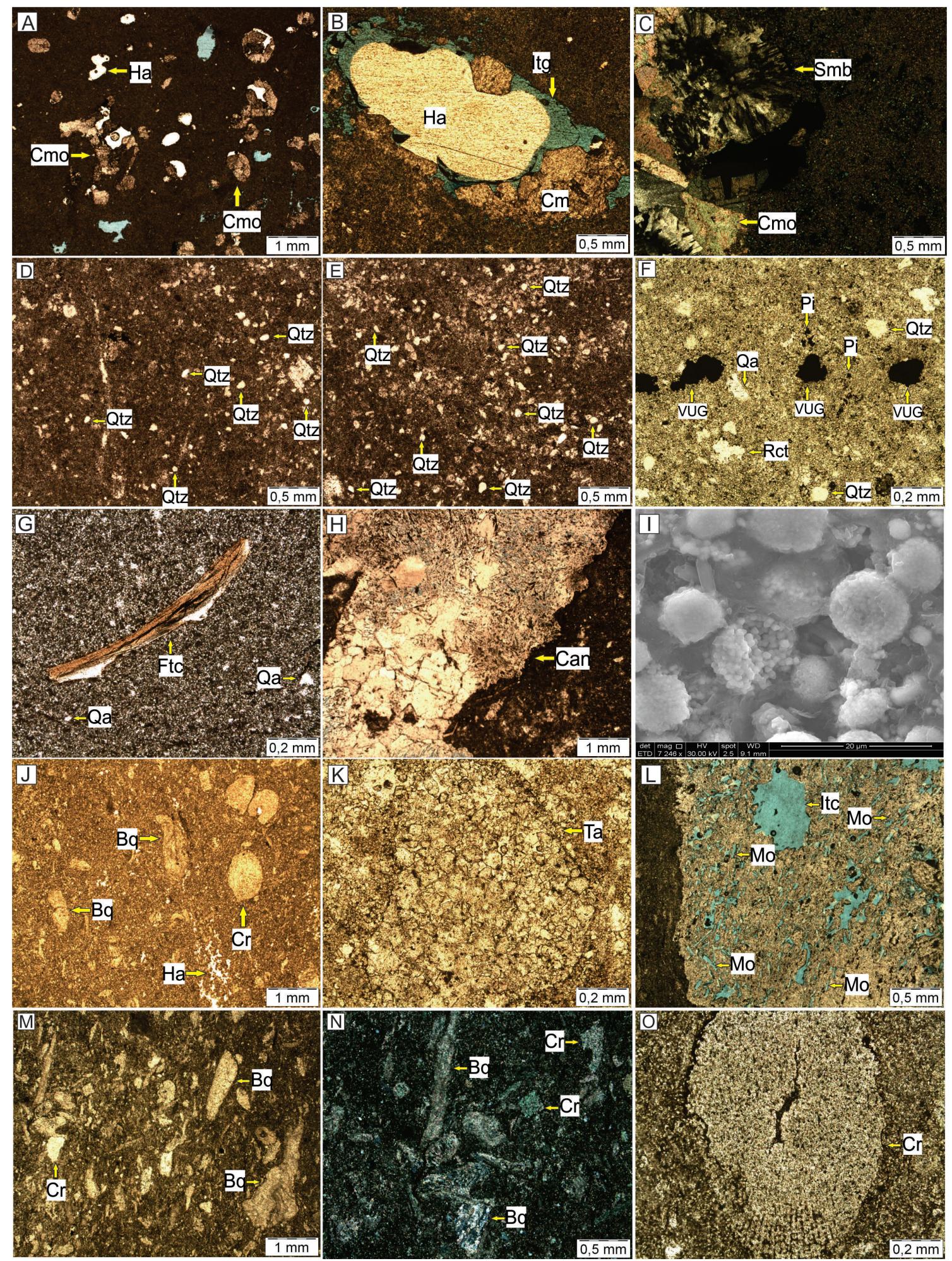

Figura 3. Fotomicrografias de seções delgadas das microfácies Mudstone com evaporitos (Me), Wackestone com terrígenos (Wt), Wackestone com quartzo autigênico e fitoclasto (Wqf), Wackestone com braquiópodes e crinóides (Wbc) e Packstone com braquiópodes (Pb). Microfácies Me: A) Arcabouço matriz suportado, grãos de halita (Ha) e cimento do tipo calcita espática com textura em mosaico (Cmo) preenchendo poros; B) Grão de halita e cimento (Cm) em poro intergranular (Itg); C) Sílica microbotrioidal (Smb) substituindo cimento. Microfácies Wt: D e E) Arcabouço matriz suportado, grãos detríticos de quartzo (Qtz) e intensa recristalização; F) Vugs (VUG), quartzo autigênico (Qa) e pequenas esferas de pirita ( $\mathrm{Pi})$. Microfácies Wqf: G) Arcabouço matriz suportado, forte recristalização, quartzo autigênico (Qa) e fitoclasto não-opaco não-bioestruturado, acastanhado e tabular (Ftc); H) Canal (Can) preenchido por cimento espático com textura em mosaico e evaporitos, os quais possuem moldes evaporíticos aciculares; I) Piritas frambóidais com cimentação calcítica entre os agregados (imagem do MEV). Microfácies Wbc: J) Arcabouço matriz suportado, fragmentos esqueletais de braquiópodes $(\mathrm{Bq})$ e crinóides $(\mathrm{Cr})$ e grãos de halita $(\mathrm{Ha})$; K) Fragmento esqueletal de coral Tabulata com seu característico padrão de simetria dos coralítos; L) Moldes evaporíticos aciculares (Mo) e poros intercristalinos (Itc). Microfácies $\mathrm{Pb}$ : M) Arcabouço grão suportado e fragmentos esqueletais de braquiópodes (Bq) e crinóides (Cr); N) Detalhe para fragmentos esqueletais de braquiópodes e crinóides em nicóis cruzados; 0) Fragmento esqueletal de crinóide (Cr). 
Figure 3. Photomicrographs of thin sections of the Mudstone with evaporites (Me), Wackestone with terrígenos (Wt), Wackestone with autigénico quartz and phytoclast (Wqf), Wackestone with brachiopods and crinoids (Wbc) and Packstone with brachiopods ( $\mathrm{Pb}$ ). Microfacies Me: A) Supported matrix framework, halite grains (Ha) and mosaic textured calcite cement (Cmo) filling pores; B) Halite grain and cement $(\mathrm{Cm})$ in intergranular pore $\mathrm{Itg}$ ); $\mathrm{C}$ ) Microbotryoidal silica $(\mathrm{Smb})$ replacing cement. Microfacies Wt: $D$ and $E$ ) Supported matrix framework, quartz detrital grains (Qtz) and intense recrystallization; F) Vugs (VUG), autigenic quartz (Qa) and small pyrite spheres (Pi). Microfacies Wqf: G) Supported matrix framework, strong recrystallization, autigenic quartz (Qa) and nonbiostructured non- opaque phytoplast, brownish and tabular (Ftc); H) Channel (Can) filled with mosaic textured spit cement and evaporites, which have acicular evaporite molds; I) Framboid pyrite with calcitic cementation between the aggregates (SEM image). Microfacies Wbc: J) Supported matrix framework, skeletal fragments of brachiopods (Bq) and crinoids (Cr) and halite grains (Ha); K) Skeletal fragment of Tabulata coral with its characteristic pattern of symmetry of corallites; L) Acicular evaporitic molds (Mo) and intercrystalline pores (Itc). Microfacies $\mathrm{Pb}$ : M) Supported grain framework and skeletal fragments of brachiopods (Bq) and crinoids (Cr); N) Detail for skeletal fragments of brachiopods and crinoids in crossed nicols; 0) Crinoid skeletal fragment (Cr).

cerca de $1 \%$ dos grãos. Apresenta coloração acinzentada, intensa recristalização, estrutura do tipo solution seams e poros intergranulares, intrapartículas, intercristalinos, além de microfraturas, canais e vugs.

Wackestone com terrígenos (Wt) (Fig. 3D-F): cerca de $60 \%$ de matriz microsparita e

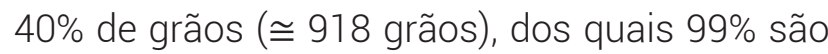
representados por clastos não-esqueletais e $1 \%$ por bioclastos. Os clastos não-esqueletais são constituídos por grãos detríticos de quartzo (54\%), quartzo autigênico (26\%), halita (17\%), pirita $(1 \%)$ e anidrita $(<1 \%)$, e os bioclastos por foraminíferos aglutinantes $(<7 \%)$. Apresenta coloração acinzentada, forte recristalização e poros intergranulares, intercristalinos e vugs.

Wackestone com quartzo autigênico e fitoclastos (Wqf) (Fig. 3G-I): cerca de 82\%

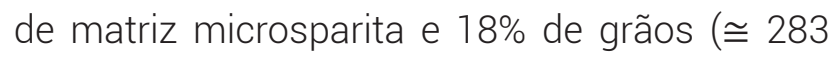
grãos), dos quais 96\% são constituídos por clastos não-esqueletais e $4 \%$ por bioclastos. Os clastos não-esqueletais são representados por quartzo autigênico (30\%), fitoclastos não-opacos não-bioestruturados (20\%), halita (18\%), pirita framboidal (1\%) e pelóides (1\%), e os bioclastos por fragmentos esqueletais de braquiópodes $(4 \%)$ e por foraminíferos aglutinantes (<1\%). Apresenta coloração acastanhada, forte recristalização, estrutura do tipo solution seams e poros intercristalinos, moldes evaporíticos, microfraturas, canais e vugs.

\section{Wackestone com braquiópodes e} crinóides (Wbc) (Fig. 3J-L): cerca de 75\% de matriz micrítica e $25 \%$ de grãos (气926 grãos), dos quais $91 \%$ são representados por bioclastos e $9 \%$ por clastos não-esqueletais. Os bioclastos são representados por restos e fragmentos esqueletais de braquiópodes (52\%), crinóides (38\%), foraminíferos fusulínideos (5\%), corais Rugosa coloniais (2\%), bivalves (1\%), equinoides $(1 \%)$, gastrópodes (1\%) e corais Tabulata (1\%), e os clastos não-esqueletais são constituídos por quartzo autigênico (6\%) e halita (2\%). Apresenta coloração acastanhada, alta recristalização e micritização, poros intergranulares, intercristalinos, moldes evaporíticos e de fragmentos esqueletais, microfraturas, canais e vugs.

Packstone com braquiópodes (Pb) (Fig. 3M-0): cerca de $30 \%$ de matriz microsparita e $70 \%$ de grãos (@1526 grãos), dos quais $85 \%$ são representados por bioclastos e 15\% por clastos não-esqueletais. Os bioclastos são constituídos por restos e fragmentos esqueletais de braquiópodes (48\%), crinóides (22\%), foraminíferos fusulinídeos (11\%), bivalves (1\%), briozoários (1\%), gastrópodes (1\%) e equinóides, foraminíferos aglutinantes, ostracodes, coral Rugosa e trilobitas, os quais perfazem cerca de $1 \%$. Os clastos não-esqueletais são constituídos por quartzo autigênico (8\%), intraclastos (3\%), pelóides (1\%) e halita (1\%). Apresenta coloração acinzentada, forte recristalização, estruturas como solution seams, poros intergranulares, intrapartículas, intercristalinos, microfraturas e vugs.

Grainstone com braquiópodes (Gb) (Fig. 4A-C): cerca de $3 \%$ de matriz micrítica e $97 \%$ de grãos (@2276 grãos), dos quais 91\% são representados por bioclastos e $9 \%$ por clastos não-esqueletais. Os bioclastos são constituídos por restos e fragmentos esqueletais de braquiópodes (53\%), crinóides (24\%), foraminíferos fusulínideos (10\%), bivalves 
(1\%), gastrópodes (1\%) e foraminíferos aglutinantes (1\%). Briozoários, equinoides, ostracodes, trilobitas e corais Rugosa coloniais, perfazem somados cerca de $1 \%$. Os clastos não-esqueletais são constituídos por quartzo autigênico (5\%), halita (1\%), intraclastos (1\%), pelóides (1\%) e oncólitos (1\%). Apresenta coloração acastanhada, estruturas como solution seams, poros intergranulares, intrapartículas, microfraturas e vugs. Em alguns bioclastos é observada a recristalização dos grãos, com a substituição por sílica.

Grainstone com fusulinídeos (Gf) (Fig. 4DF): cerca de $2 \%$ de matriz micrítica e $98 \%$ de grãos

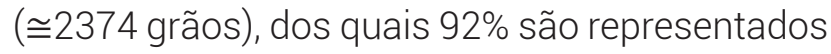
por bioclastos e $8 \%$ por clastos não-esqueletais. Os bioclastos são constituídos por fragmentos esqueletais e restos de foraminíferos fusulinídeos (66\%), braquiópodes (14\%), crinóides (6\%), foraminíferos miliolídeos (2\%) bivalves (2\%), corais Rugosa coloniais (1\%) e foraminíferos aglutinantes, equinóides, briozoários, gastrópodes, ostracodes e problemática, os quais somados perfazem cerca de $1 \%$. Os clastos não-esqueletais são constituídos por pelóides (6\%), quartzo autigênico (1\%) e intraclastos (1\%). Apresenta coloração acastanhada, estruturas do tipo solution seams, poros intergranulares e vugs.

Grainstone com aglutinantes (Ga) (Fig. 4GI): cerca de $2 \%$ de matriz micrítica e $98 \%$ de grãos

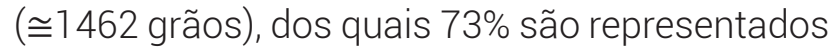
por bioclastos e $27 \%$ por clastos nãoesqueletais. Os bioclastos são constituídos por fragmentos esqueletais e restos de foraminíferos aglutinantes (58\%), foraminíferos fusulínideos (5\%), crinóides (2\%), braquiópodes (1\%), e equinóides, gastrópodes, corais Rugosa coloniais e bivalves, os quais somados perfazem cerca de 1\%. Os clastos não-esqueletais são constituídos por pelóides (12\%), halita (8\%), oncólitos (4\%), intraclastos (2\%), e quartzo autigênico (1\%). Apresenta coloração acastanhada, intensa micritização e recristalização, além de estruturas do tipo solution seams, poros intergranulares, intrapartículas, intercristalinos, microfraturas e vugs.

Boundstone com intraclastos (Bi) (Fig. 4J-L): caracterizada por estrutura primária que aparenta ligação orgânica sindeposicional, apresentando cerca de $88 \%$ de matriz micrítica e $12 \%$ de grãos ( $\cong 275$ grãos, os quais seguem a orientação da estrutura organo-sedimentar). Dentre os grãos, $60 \%$ são constituídos por clastos não-esqueletais e $40 \%$ por bioclastos. Os grãos não-esqueletais são representados por intraclastos do tipo "rip up clast" (47\%), halita (9\%), quartzo autigênico (3\%) e pirita (1\%), e os bioclastos por restos e fragmentos esqueletais de braquiópodes (23\%), crinóides (9\%), fusulinídeos (7\%), e bivalves, gastrópodes, coral Rugosa e trilobitas, os quais somados perfazem cerca de 1\%. Apresenta coloração acastanhada, microfraturas e vugs.

\section{2 Índice de energia, microbiofácies e associações de grãos não-esqueletais}

A integração dos dados paleoecológicos com a caracterização do arcabouço das rochas permitiu o estabelecimento das seguintes categorias de energia hidrodinâmica para as microfácies (Quadro 1).

A partir do levantamento paleoecológico e da análise dos padrões de distribuição e frequência dos grupos fósseis identificados nas seções estudadas, foi possível identificar quatro microbiofácies, as quais são sumarizadas na tabela 1.

A Microbiofácies 01 caracteriza-se pelo predomínio de braquiópodes (50\%), crinóides

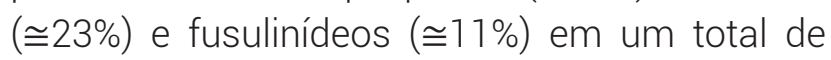

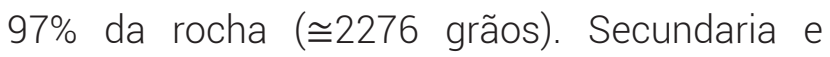

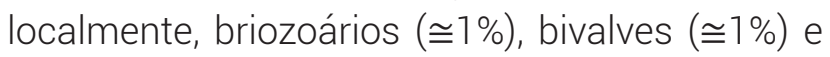

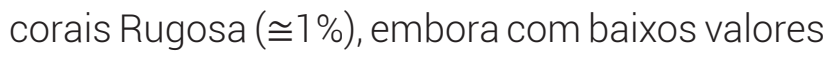
de frequência, também apresentam trends significativos. Foi identificada nas microfácies $\mathrm{Pb}$ e $\mathrm{Gb}$.

A Microbiofácies 02 é representada pelo predomínio de foraminíferos fusulinídeos (气65\%),

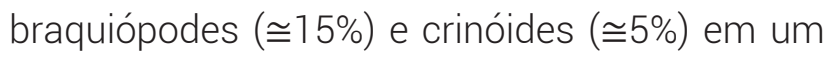
total de $98 \%$ da rocha ( $\cong 2374$ grãos). Secundaria

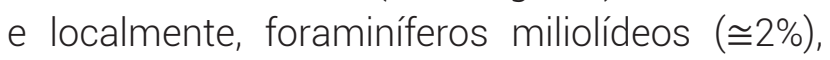
bivalves $(\cong 2 \%)$ e corais Rugosa coloniais ( $\cong 1 \%)$, embora com baixos valores de frequência, também apresentam trends significativos. Foi verificada na microfácies Gf.

A Microbiofácies $\mathbf{0 3}$ distingui-se pelo 

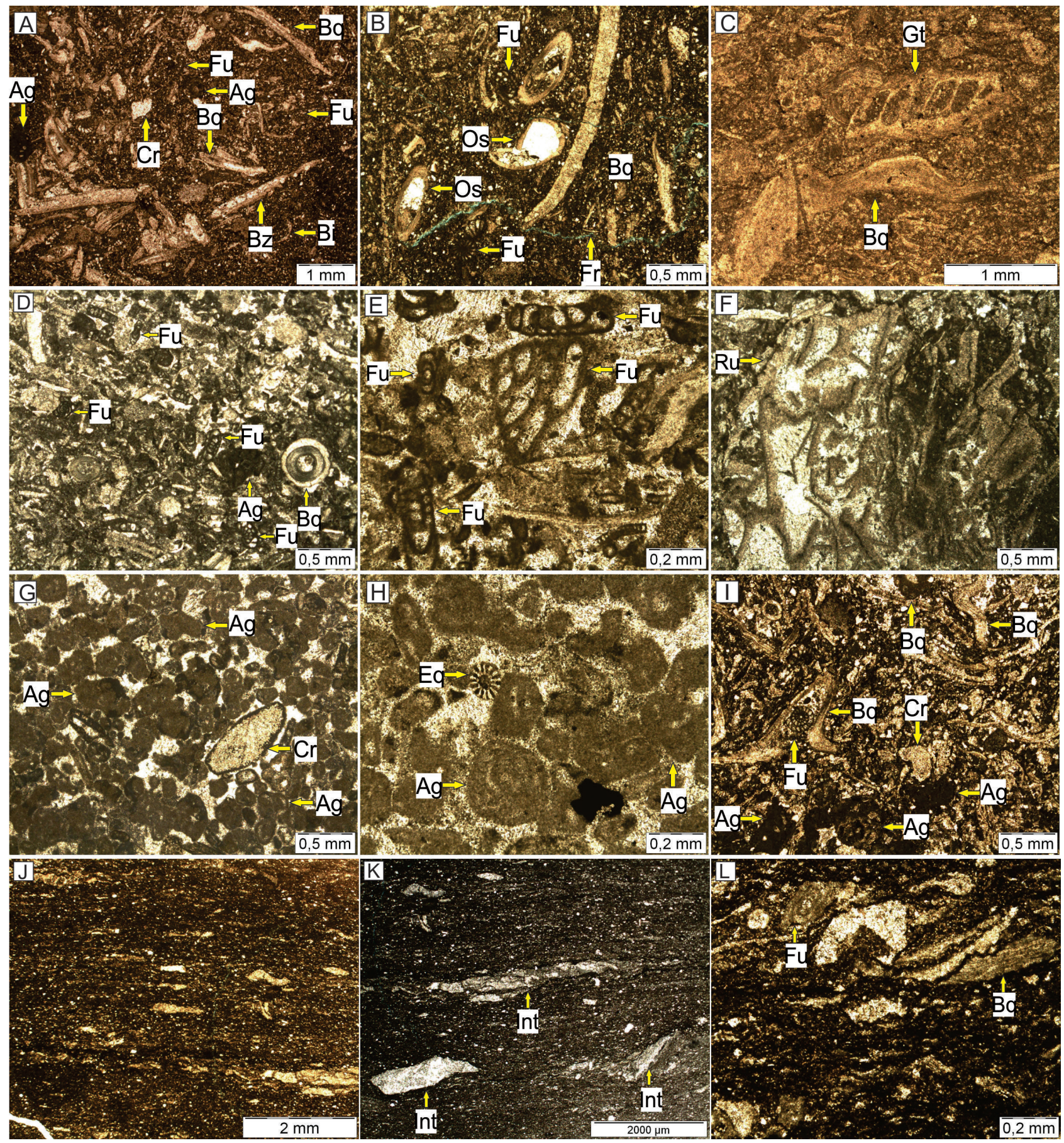

Figura 4. Fotomicrografias de seções delgadas das microfácies Grainstone com braquiópodes (Gb), Grainstone com fusulinídeos (Gf), Grainstone com aglutinantes (Ga) e Boundstone com intraclastos (Bi). Microfácies Gb: A) Arcabouço grão suportado, mal selecionamento, fragmentos esqueletais de braquuiópodes (Bq), crinóides (Cr), bivalves (Bi), briozoários (Bz), fusulinídeos (Fu) e aglutinantes ( $\mathrm{Ag}$ ); B) Fragmentos esqueletais de ostracodes (Os) com seus pares de conchas articuladas características, braquiópodes $(\mathrm{Bq})$ e microfratura $(\mathrm{Fr}) ; \mathrm{C})$ Fragmentos esqueletais de braquiópodes (Bq) e gastrópodes (Gt). Microfácies Gf: D) Arcabouço grão suportado, foraminíferos fusulinídeos (Fu), aglutinantes (Ag) e fragmentos esqueletais de braquiópodes (Bq); E) Detalhe para foraminíferos fusulinídeos (Fu) e forte cimentação; F) Fragmento esqueletal de coral Rugosa colonial com suas ramificações irregulares e corallitos de formas poligonais. Microfácies Ga: G) Arcabouço grão suportado, forte recristalização e micritização, foraminíferos aglutinantes (Ag) e fragmento esqueletal de crinóide $(\mathrm{Cr}) ; \mathrm{H})$ Foraminíferos aglutinantes com o padrão de enrolamento da câmara e fragmento esqueletal de equinoide (Eq) com sua característica simetria; I) Braquiópodes (Bq), crinóides (Cr), fusulinídeos (Fu) e aglutinantes (Ag). Microfácies Bi: J) Ligação organo-sedimentar e clastos dispostos segundo a orientação desta ligação; K) Intraclastos alongados com terminações subangulosos, aparentemente caracterizam "rip-up clast"; L) Braquiópodes (Bq) e fusulinídeos (Fu). 
Figure 4. Photomicrographs of thin sections of the Grainstone microfacies with brachiopods (Gb), Grainstone with fusulinids (Gf), Grainstone with binders (Ga) and Boundstone with intraclasts (Bi). Microfacies Gb: A) Supported grain framework, poor selection, skeletal fragments of braquuiopodes (Bq), crinoids (Cr), bivalves (Bi), bryozoans (Bz), fusulinids (Fu) and agglutinants (Ag); B) Skeletal fragments of ostracods (Os) with their characteristic pairs of articulated shells, brachyopores $(\mathrm{Bq})$ and microfracture $(\mathrm{Fr}) ; \mathrm{C})$ Skeletal fragments of brachiopods $(\mathrm{Bq})$ and gastropods (Gt). Microfacies $\mathrm{Gf}$ : D) Supported grain framework, fusulinid foraminifers (Fu), agglutinants (Ag) and skeletal fragments of brachiopods (Bq); $E$ ) Detail for fusininid foraminifera (Fu) and strong cementation; F) Coral skeletal fragment of colonial rugosa with its irregular ramifications and corallitos of polygonal forms. Microfacies Ga: G) Supported grain framework, strong recrystallization and micritization, foraminifera agglutinating $(\mathrm{Ag})$ and skeletal crinoid fragment $(\mathrm{Cr}) ; \mathrm{H})$ Foraminifera binders with chamber winding pattern and equinoid skeletal fragment $(\mathrm{Eq})$ with their characteristic symmetry; I) Brachiopod (Bq), crinoid (Cr), fusulinid (Fu) and agglutinating (Ag). Microfacies Bi: J) Organo-sedimentary bond and clasts arranged according to the orientation of this bond; K) Elongate intraclastos with subangulo terminations, apparently characterize "rip-up clast"; L) Brachiopods (Bq) and fusulinid (Fu).

Quadro 1. Classificação do índice de energia de acordo com Plumley et al. (1962, apud Flügel, 2010).

Chart 1. Classification of the energy index according to Plumley et al. (1962, apud Flügel, 2010).

\begin{tabular}{|c|c|c|}
\hline Categorias & Características & Microfácies \\
\hline Tipo I & águas calmas & $\mathrm{Me}, \mathrm{Wt}, \mathrm{Wqf}, \mathrm{Wb}$ e $\mathrm{Bi}$ \\
\hline Tipo II & agitado e intermitente & - \\
\hline Tipo III & levemente agitado & - \\
\hline Tipo IV & moderadamente agitado & Pb e Gf \\
\hline Tipo V & fortemente agitado & Gb e Ga \\
\hline
\end{tabular}

Tabela 1. Características das microbiofácies, com ênfase para os bioclastos predominantes e secundários e para as microfácies em que são reconhecidas.

Table 1. Characteristics of the microbiofacies, with emphasis on the predominant and secondary bioclasts and the microfacies in which they are recognized.

\begin{tabular}{|c|c|c|c|c|c|c|}
\hline $\begin{array}{c}\text { Microbiofácie } \\
s\end{array}$ & $\begin{array}{l}\text { Grãos } \\
\text { totais }\end{array}$ & $\begin{array}{l}\% \text { da } \\
\text { rocha }\end{array}$ & $\begin{array}{c}\text { Bioclastos } \\
\text { predominantes }\end{array}$ & $\begin{array}{c}\text { Bioclastos } \\
\text { secundários }\end{array}$ & Microfácies & Energia \\
\hline $\begin{array}{c}\text { Microbiofácies } \\
01\end{array}$ & $\cong 2276$ & $97 \%$ & 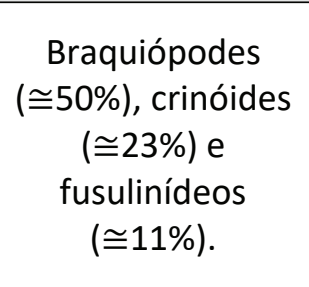 & 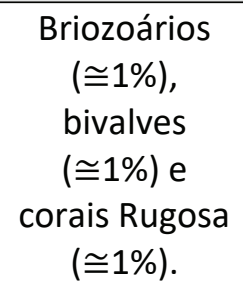 & $\mathrm{Pb}$ e Gb & $\begin{array}{c}\text { Moderada a } \\
\text { fortemente } \\
\text { agitada }\end{array}$ \\
\hline $\begin{array}{c}\text { Microbiofácies } \\
02\end{array}$ & $\cong 2374$ & $98 \%$ & 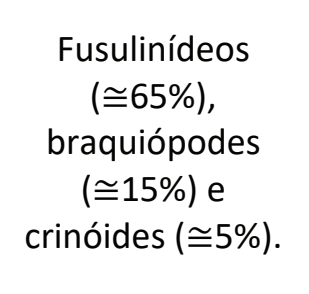 & 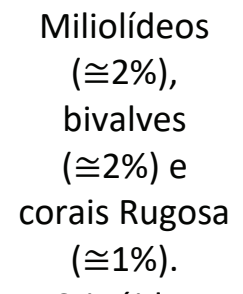 & Gf & $\begin{array}{l}\text { Moderada- } \\
\text { mente } \\
\text { agitada }\end{array}$ \\
\hline $\begin{array}{c}\text { Microbiofácies } \\
03\end{array}$ & $\cong 1462$ & $98 \%$ & 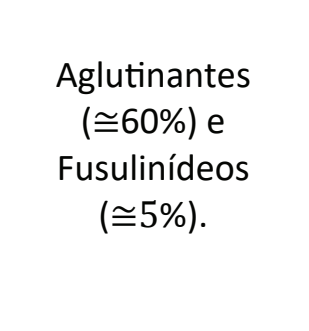 & 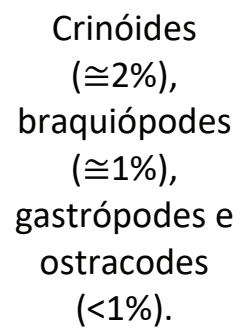 & Ga & $\begin{array}{c}\text { Fortemente } \\
\text { agitada }\end{array}$ \\
\hline $\begin{array}{c}\text { Microbiofácies } \\
04\end{array}$ & $\cong 926$ & $25 \%$ & 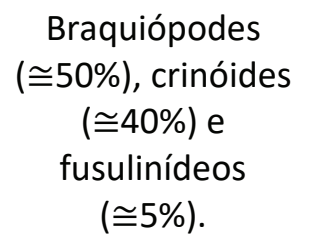 & $\begin{array}{c}\text { Corais Rugosa } \\
\text { + equinoides } \\
\text { + corais } \\
\text { Tabulata } \\
\text { (<2\%). }\end{array}$ & Wbc & $\begin{array}{l}\text { Águas } \\
\text { calmas }\end{array}$ \\
\hline
\end{tabular}


predomínio de foraminíferos aglutinantes

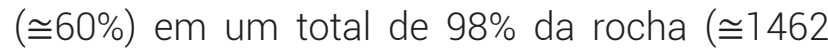
grãos). Secundaria e localmente, foraminíferos

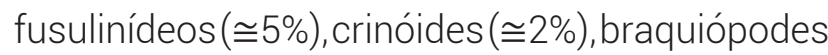

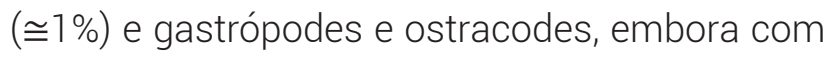
baixos valores de frequência $(<1 \%)$, apresentam tendências semelhantes à dos aglutinantes, sendo observada na microfácies Ga.

A Microbiofácies 04 é marcada pelo predomínio de braquiópodes (50\%), crinóides

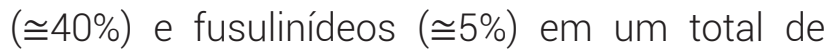

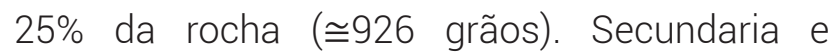
localmente, corais Rugosa, bivalves, equinoides e corais Tabulata, embora com baixos valores de frequência (<2\%), também apresentam trends significativos. Foi identificada na microfácies Wbc.

Do mesmo modo, a partir do levantamento do significado sedimentológico e da análise dos padrões de distribuição e frequência dos grãos não-esqueletais, foi possível reconhecer cinco associações principais, as quais são sumarizadas na tabela 2.

A Associação 01 caracteriza-se pelo predomínio de halita (80\%) e quartzo autigênico

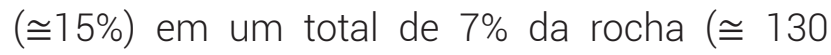

grãos), sendo identificada na microfácies Me. A Associação 02 distingui-se pelo predomínio de grãos detríticos de quartzo (气55\%), quartzo

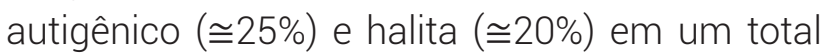
de $40 \%$ da rocha ( $\cong 918$ grãos), sendo verificada na microfácie Wt.

A Associação 03 é representada pelo

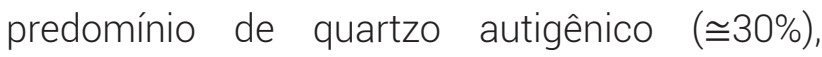

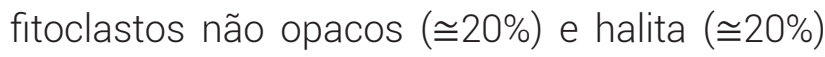

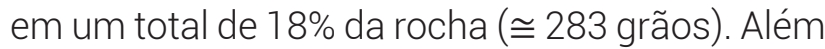
destes grãos, outro importante constituinte desta associação é a presença de pirita framboidal, por isso, embora representada por baixos valores de

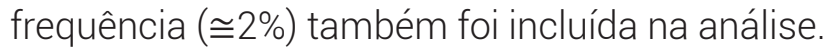
Esta associação foi observada na microfácies Wqf.

AAssociação 04 émarcada pelo predomínio

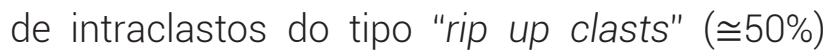

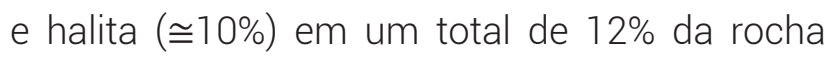

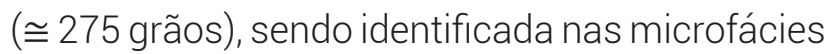
Bi. E, por fim, a Associação 05 caracteriza-se por significativa ocorrência, embora não seja

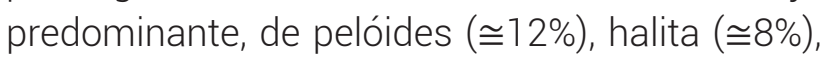

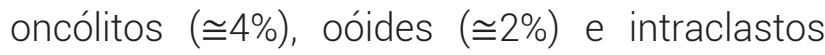

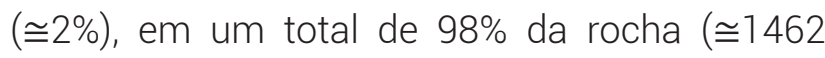
grãos), sendo verificada na microfácies $\mathrm{Ga}$.

Tabela 2. Associações de grãos não-esqueletais com as microfácies em que são reconhecidas.

Table 2. Non-skeletal grain associations with the microfacies in which they are recognized.

\begin{tabular}{|c|c|c|c|c|}
\hline Associações & $\begin{array}{l}\text { Grãos } \\
\text { totais }\end{array}$ & $\%$ da rocha & Grãos não-esqueletais & Microfácies \\
\hline $\begin{array}{l}\text { Associação } \\
01\end{array}$ & $\cong 130$ & $7 \%$ & 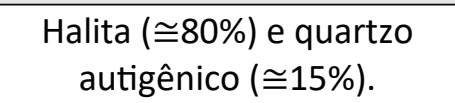 & Me \\
\hline $\begin{array}{l}\text { Associação } \\
02\end{array}$ & $\cong 918$ & $40 \%$ & 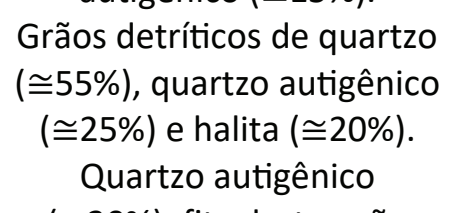 & Wt \\
\hline $\begin{array}{l}\text { Associação } \\
03\end{array}$ & $\cong 283$ & $18 \%$ & 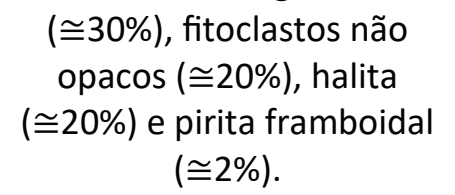 & Wqf \\
\hline $\begin{array}{l}\text { Associação } \\
04\end{array}$ & $\cong 275$ & $12 \%$ & 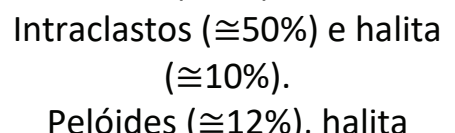 & $\mathrm{Bi}$ \\
\hline $\begin{array}{l}\text { Associação } \\
05\end{array}$ & $\cong 1462$ & $98 \%$ & 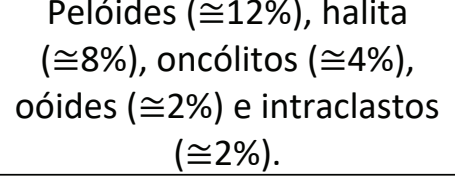 & Ga \\
\hline
\end{tabular}




\section{Discussão dos resultados}

\subsection{Associações de microfácies}

Da integração entre as microfácies identificadas, o índice de energia do meio, a individualização de microbiofáceis e associações de grãos não-esqueletais, foram interpretados conjuntos de parâmetros ambientais específicos, cuja evolução está ligada à configurações deposicionais específicas e, com isso, foram identificadas cinco associações de microfácies: AMF-01, AMF-02, AMF-03, AMF-04 e AMF-05, assim caracterizadas e interpretadas (Quadro 2).

A partir da integração e da interpretação dos dados levantados e com base nos estudos geológicos prévios da Bacia do Amazonas (e. g., Caputo, 1984; Silva, 1996; Matsuda, 2002; Moutinho, 2006), admite-se o desenvolvimento de uma plataforma carbonática intracratônica durante o Neopensilvaniano da bacia. Segundo Ross \& Ross (1990, apud Matsuda, 2002), esta plataforma localizava-se em baixas a médias latitudes, entre aproximadamente $30^{\circ}$ e $35^{\circ} \mathrm{S}$.
Estudos paleoambientais desenvolvidos em carbonatos pensilvanianos da Formação Itaituba (e. g., Carozzi et al., 1972; Silva, 1996; Matsuda, 2002; Moutinho, 2006; Neves, 2009; Lima, 2010; Silva, 2014; Silva et al., 2015; Souza; 2016; Moutinho et al., 2016b; Teixeira, 2017), sugerem que a sedimentação carbonática, característica da Formação Itaituba, foi amplamente dominada por maré, sendo comumente relacionada com três zonas deposicionais distintas: supramaré, intermaré e inframaré.

Quanto ao perfil deposicional, de acordo com Matsuda (2002), a plataforma carbonática Neopensilvaniana da bacia seria do tipo rampa carbonática, similar ao documentados por Irwin (1965), Ahr (1973), Shin (1983), Read (1985) e Burchette \& Wright (1992), tendo como exemplo recente a costa do Golfo Pérsico na região de Abu Dhabi.

Matsuda (2002), baseado em analogias e nos resultados das associações de microfácies, elaborou um modelo idealizado do perfil deposicional do tipo rampa, no qual reconheceu sete domínios deposicionais para a sequência carbonática pensilvaniana da Bacia do Amazonas:

Quadro 2. Associações de microfácies (AMF) com as microbiofácies e associações de grãos não-esqueletais que as compõem, bem como com o índice de energia hidrodinâmica do meio, a salinidade e a zona geomorfológica interpretados e representativos dos ambientes de sedimentação inferidos para as sucessões estudadas.

Chart 2. Microfacies associations (AMF) with the microbiofacies and non-skeletal grain associations that compose them, as well as the hydrodynamic energy index of the medium, the salinity and the geomorphological zone interpreted and representative of the sedimentation environments inferred for the studied sequences.

\begin{tabular}{|c|c|c|c|c|c|c|}
\hline AMF & Microbiofácies & $\begin{array}{l}\text { Associação } \\
\text { de grãos } \\
\text { não- } \\
\text { esqueletais }\end{array}$ & $\begin{array}{c}\text { Índice } \\
\text { de } \\
\text { energia }\end{array}$ & Salinidade & $\begin{array}{c}\text { Zona } \\
\text { geomorfoló- } \\
\text { gica }\end{array}$ & $\begin{array}{c}\text { Ambiente de } \\
\text { sedimentação }\end{array}$ \\
\hline $\begin{array}{c}\text { AMF- } \\
01\end{array}$ & - & $\begin{array}{l}\text { Associação } \\
01\end{array}$ & Tipo I & hiperhalina & $\begin{array}{c}\text { Supramaré/ } \\
\text { Intermaré } \\
\text { Superior } \\
\end{array}$ & $\begin{array}{c}\text { Sabhka costeira } \\
\text { semi-restrita }\end{array}$ \\
\hline $\begin{array}{c}\text { AMF- } \\
02\end{array}$ & - & $\begin{array}{l}\text { Associação } \\
02,03 \text { e } 04\end{array}$ & Tipo I & $\begin{array}{l}\text { mixohalina } \\
\text { tendendo a } \\
\text { hiperhalina } \\
\end{array}$ & $\begin{array}{c}\text { Supramaré/ } \\
\text { Intermaré } \\
\text { Superior }\end{array}$ & $\begin{array}{l}\text { Planície de } \\
\text { maré }\end{array}$ \\
\hline $\begin{array}{l}\text { AMF- } \\
03\end{array}$ & $\begin{array}{c}\text { Microbiofácies } \\
04 \\
\end{array}$ & - & Tipo I & euhalina & $\begin{array}{l}\text { Intermaré } \\
\text { Superior }\end{array}$ & $\begin{array}{l}\text { Laguna semi- } \\
\text { restrita }\end{array}$ \\
\hline $\begin{array}{c}\text { AMF- } \\
04\end{array}$ & $\begin{array}{c}\text { Microbiofácies } \\
03\end{array}$ & $\begin{array}{c}\text { Associação } \\
05\end{array}$ & Tipo V & $\begin{array}{l}\text { mixohalina } \\
\text { tendendo a } \\
\text { hiperhalina } \\
\end{array}$ & $\begin{array}{l}\text { Intermaré } \\
\text { Inferior/ } \\
\text { Inframaré }\end{array}$ & Canais de maré \\
\hline $\begin{array}{l}\text { AMF- } \\
05\end{array}$ & $\begin{array}{c}\text { Microbiofácies } \\
01 \text { e } 02\end{array}$ & - & $\begin{array}{l}\text { Tipo IV } \\
\text { e Tipo V }\end{array}$ & euhalina & $\begin{array}{l}\text { Intermaré } \\
\text { Inferior/ } \\
\text { Inframaré }\end{array}$ & $\begin{array}{c}\text { Barras } \\
\text { bioclásticas }\end{array}$ \\
\hline
\end{tabular}


plataforma externa (inframaré), barra bioclástica de intermaré e inframaré, laguna protegida de intermaré, planície de intermaré e supramaré, sabkhas de supramaré, planície de supramaré e continental.

Neste trabalho, a partir da identificação e caracterização de cinco associações de microfácies (AMF-01, AMF-02, AMF-03, AMF-04 e AMF-05), foram reconhecidos quatro ambientes de sedimentação: barras bioclástica de intermaré e inframaré, laguna semi-restrita de intermaré, planície de maré e sabkha de supramaré/ intermaré superior, cuja caracterização é sumarizada a seguir.

A AMF-01 é identificada como um ambiente marinho proximal e hiperhalino, aqui inferido como sabkha costeira semi-restrita (Zona de Supramaré/Intermaré Superior), sob regime climático semiárido. Entre outros aspectos, esta interpretação baseia-se no significado sedimentológico da halita e do quartzo autigênico (Associação 01), na baixa diversidade e abundância de organismos bentônicos e na textura matriz suportada na microfácies Me.

A formação de halita é relacionada a condições deelevada salinidadee aridezclimática, associadas a restrições de circulação de águas (Aquilano et al., 2016), sendo que cubos e formas esqueletais de halita em matriz carbonática podem ser indicativas de ambiente marginal do tipo sabkha (Silva et al., 2000). O quartzo autigênico tem sua formação relacionada ao input fluvial de soluções de intemperismo continental em climas semi-áridos (Flügel, 2010). A sílica microbotrioidal (nódulos de sílica), também observada, pode ser interpretada como produto da substituição de evaporitos (Moutinho, 2006). Isto, somado ao arcabouço matriz suportada da rocha, indica condições hidrodinâmicas de baixa energia, sustentando as interpretações.

O domínio de sabkha, identificado por Matsuda (2002) e Moutinho (2006), possui como microfácies diagnósticas os dolomitos laminados e dolomitos lamosos, sendo considerado como uma planície de maré marinha marginal evaporítica com condições de hipersalinidade predominantes. Embora neste trabalho não tenha sido possível empregar técnicas de reconhecimento de dolomitos, observa-se na microfácies mudstone com evaporitos forte recristalização e semelhança com os dolomitos característicos deste domínio, além da ocorrência de evaporitos e sílica microbotrioidal (produto da substituição de evaporitos), o que fortalece as interpretações de hipersalinidade relacionadas a este ambiente.

A AMF-02 é interpretada como um ambiente marinho proximal, com contribuições continentais e/ou transicionais, salinidade possivelmente mixohalina tendendo a hiperhalina, sob condições climáticas semiáridas, oxigenadas e com índice de energia típico de águas calmas, inferido como planície de maré (Zona de Supramaré/Intermaré Superior). Esta interpretação baseia-se, principalmente, no significado sedimentológico do quartzo detrítico, fitoclasto não-opaco, pirita framboidal e "rip up clast" (Associações 02, 03 e 04), na baixa diversidade e abundância de organismos bentônicos e na textura matriz suportada nas microfácies Wt, Wqf e Bi.

O predomínio de grãos detríticos de quartzo na Associação 02 sugere a contribuição de ambientes continentais e/ou transicionais na bacia sedimentar, pois, segundo Flügel (2010), em áreas marinhas pouco profundas, a entrada de sílica terrígena é uma fonte importante de sedimentos e sua gênese comumente deve-se ao intemperismo em áreas fontes continentais e/ ou transicionais, seguidas do transporte eólico e/ ou fluvial para o ambiente de sedimentação.

$\mathrm{Na}$ Associação 03, a significativa concentração de fitoclastos não-opacos nãobioestruturados é indicativa de porções mais proximais e de contribuição continental (Menezes \& Mendonça-Filho, 2004; Mendes, 2015). As piritas framboidais, por possuírem, em média, diâmetros com cerca de 10 um (estimativa visual, realizada através da escala do MEV), sugerem sua formação dentro do sedimento em condições paleoambientais de águas oxigenadas, o que leva a interpretação de uma origem diagenética, de acordo com Suits \& Wilkin (1998).

Já o predomínio de intraclastos do tipo "ripup clasts" na Associação 04 sugere um ambiente marinho proximal para esta associação, pois, segundo Flügel (2010), a origem destes grãos é comumente associada a dessecação de 
carbonatos em ambientes de supramaré.

Segundo Carozzi et al. (1972), Matsuda (2002), Moutinho (2006), Lima (2010) e Silva (2014), o domínio de planície de maré é associado a microbialitos, evaporitos, grãos terrígenos, bioclastos transportados por correntes de maré e tempestade, feições de ressecamento, pseudomorfos de evaporitos, quartzo detrítico e restos de plantas. Associando a este domínio as microfácies laminito microbial, dolomudstone e dolomudstone poroso, dolomito fino laminado, dolomudstone com grãos terrígenos e dolomito fino silicificado. As feições e microfácies, relacionadas por estes autores ao domínio de planície de maré, correlacionam-se bem com as encontradas neste trabalho (wackestone com terrígenos, wackestone com braquiópodes e fitoclastos e Boundstone com intraclastos).

A AMF-03 é interpretada como de ambientes marinhos neríticos, com águas temperadas a quentes, euhalinas, fóticas, eutróficas, pouco profundas e com energia hidrodinâmica característica de águas calmas, aqui inferida como laguna semi-restrita (Zona de Intermaré Superior). Entre outros aspectos, esta interpretação baseia-se, particularmente, na paleoecologia de braquiópodes, crinoides, fusulinídeos, corais Rugosa, equinoides e corais Tabulata (Biofáceis 04) e no arcabouço matriz suportado das rochas da microfácies Wbc.

A frequência de braquiópodes, crinóides, fusulinídeos e corais Rugosa sugere ambiente euhalino, fótico, aeróbico e de águas temperadas a quentes (Scholle \& Ulmer-Scholle, 2003; Flügel, 2010). Os equinoides, por sua vez, indicam ambientes rasos ( $<100 \mathrm{~m}$ de profundidade) com águas temperadas a quentes (Villalba, 2009). Já os corais Tabulata reforçam a ideia de ambiente euhalino e fótico, devido a suposta relação de simbiose com algas fotossintetizantes (Scholle \& Ulmer-Scholle, 2003; Braga et al., 2009).

Corais Tabulata sugerem baixa energia, já que são raramente encontrados em ambientes de alta energia (Clarkson, 2007), uma interpretação que também é sustentada pelo arcabouço matriz suportado das rochas.

O domínio de laguna protegida de intermaré, identificado por Matsuda (2002) e também descrito por Moutinho (2006), Neves
(2009), Lima (2010), Silva (2014), Souza (2016) e Teixeira (2017), associa aos ambientes lagunares de baixa energia e semi-restritos às microfácies wackestone bioclástico, mudstone bioclástico peloidal, mudstone bioclástico com terrígenos a ostracodes, wackestone bioclástico, packstone bioclástico a equinodermas, floatstone com braquiópodes, wackestone com braquiópodes e wackestone recristalizado. Neste trabalho a microfácies wackestone com braquiópodes e crinoides, conforme observado acima, apresenta características comuns às microfácies relacionadas ao domínio de lagunas por estes autores.

A AMF-04 é caracterizada pela influência de correntes de maré, com energia hidrodinâmica fortemente agitada e salinidade tendendo de mixohalina a hiperhalina, o que aponta para um ambiente de canais de maré (Zona de Intermaré Inferior/Inframaré). Esta interpretação baseia-se, principalmente, no significado paleoecológico dos foraminíferos aglutinantes, gastrópodes e ostracodes (Biofáceis 03), no significado sedimentológico de pelóides, oncólitos, oóides e intraclastos (Associação 05) e na textura grão suportada das rochas da microfácies Ga.

Foraminíferos aglutinantes neríticos são em geral eurialinos e comumente encontrados em ambientes marinhos marginais influenciados por maré, tais como pântanos, canais de maré e baías interdistributárias (Wightman et al.,1994). A associação com gastrópodes e ostracodes, também considerados eurialinos e comuns em ambientes em que há flutuações de salinidade, reforçam essa ideia (Gainey Jr. \& Greenberg, 1977; Gili \& Martinell, 2009; Posada et al., 2009, Kültz, 2015). Assim, quanto a salinidade, sugere-se um ambiente variando de mixohalino a hiperhalino.

Segundo Flügel (2010), a ocorrência de pelóides e oncólitos pode estar relacionada à influência de correntes de marés, enquanto que os oóides podem estar ligados tanto a condições hidrodinâmicas quanto a variações de salinidade e, os intraclastos, por sua vez, podem ter sua natureza na erosão e retrabalhamento carbonático por correntes de maré. Deste modo, a interpretação de um ambiente influenciado por maré para a associação destes grãos é condizente com o significado sedimentólogico 
associado a eles.

Por outro lado, não se observa o detalhamento de fácies e/ou microfácies relacionadas ao domínio de canais de maré na literatura da Formação Itaituba. Porém, considerando o que foi levantado sobre a paleoecologia dos táxons e sobre o significado sedimentológicos dos grãos não-esqueletais identificados neste trabalho, sugere-se este ambiente de sedimentação. Além disso, o posicionamento deste ambiente dentro da zona de intermaré inferior/inframaré corresponde a zona comumente relacionada ao domínio de barras bioclásticas na literatura.

Deste modo, é aqui proposta uma configuração de canais de maré que segmentam os depósitos de barras bioclástica nas zonas de intermaré inferior/inframaré, que, de acordo com Carozzi et al. (1972), Figueiras (1983), Silva (1996), Matsuda (2002), Neves (2009), Lima (2010), Silva (2014), Souza (2016) e Teixeira (2017), condiz com as interpretações de microfácies relacionadas a este domínio paleoambiental (e. g., packstone a foraminíferos, grainstone bioclástico com foraminíferos, grainstone bioclástico oolítico, grainstone peloidal oolítico, grainstone oolítico e grainstone com oóides).

A AMF-05 é interpretada como de ambiente com salinidade exclusivamente euhalina, substrato rígido, eutrófico, fótico, com águas temperadas a quentes e condições hidrodinâmicas moderadas a elevadas, aqui inferido como barras bioclásticas (Zona de Intermaré Inferior/Inframaré). Esta interpretação baseia-se, principalmente, na paleoecologia de braquiópodes, crinoides, fusulinídeos, briozoários, bivalves, corais Rugosa e foraminíferos miliolídeos (Biofáceis 01 e 02) e na textura grão suportada das rochas das microfácies $\mathrm{Gb}, \mathrm{Pb}$ e Gf.

Braquiópodes, crinoides, briozoários e corais Rugosa sugerem substratos rígidos, por serem bentônicos sésseis e suspensívoros (Flügel, 2010; Pereira, 2011). Quanto à salinidade, braquiópodes, crinóides, foraminíferos fusulinídeos e corais Rugosa sugerem um ambiente euhalino, pois são organismos estenoalinos, assim como briozoários e bivalves, que embora sejam eurihalinos, no carbonífero foram preferencialmente euhalinos (Gainey Jr. \& Greenberg, 1977; Kültz, 2015).

No que se refere à inferência da zona fótica, a associação destes organismos é interpretada como característica destas condições de luminosidade (Klemm et al., 2008; Nichols, 2009; Flügel, 2010). Além disso, a interpretação desta zona de radiação é reforçada pela representativa frequência de fusulinídeos, organismos que, de acordo com BouDagher-Fadel (2008), são comumente associados a águas rasas fóticas em função de seu diminuto tamanho e por serem interpretados como hospedeiros de algas fotossintetizantes, com as quais desenvolvem relação de simbiose.

Quanto à oxigenação, a fauna bentônica diversa e abundante sugere um paleoambiente dentro da zona aeróbica, já que a oxigenação é um fator bio-limitante para invertebrados marinhos (Clark \& Mosier, 1989; Boyer \& Droser, 2009; Nichols, 2009; Flügel, 2010). Em relação à temperatura da massa d'água (um dos fatores mais importantes no controle de processos vitais e, portanto, na distribuição dos organismos), esta associação de invertebrados marinhos bentônicos durante o Carbonífero sugere águas temperadas a quentes (Flügel, 2010).

No que se refere à energia hidrodinâmica do meio, leves diferenças são observadas entre as microfácies que compõem AMF-05, distinguindose porções mais distais e outras mais proximais, porém ambas dentro do mesmo domínio ambiental. Nesse sentido, a paleoecologia de braquiópodes e crinoides, grupos predominantes nas microfácies Pb e Gb (Biofáceis 01), somada a textura grão suportada das rochas, a intensa fragmentação e mal selecionamento destas rochas, sugerem condições hidrodinâmicas de elevada energia, como também, sedimentação em porções mais distais da bacia. Por sua vez, a paleoecologia dos fusulinídeos e o predomínio de formas com testas alongadas, (indicativas de um ambiente de menor energia e possivelmente mais restrito, segundo BouDagher-Fadel, 2008), a paleoecologia de miliolídeos (comuns em ambientes mais restritos, segundo Murray, 1970), a menor fragmentação de determinados tipos de bioclastos (e. g., fragmentos de corais Rugosa) e o maior selecionamento dos grãos na microfácies 
Gf, indicam condições hidrodinâmicas mais amenas, aqui associadas a um ambiente de barras mais proximais.

De acordo com Carozzi et al. (1972), Figueiras (1983), Silva (1996), Matsuda (2002), Neves (2009), Lima (2010), Silva (2014), Souza (2016) e Teixeira (2017), o domínio de barras bioclástica é considerado a área de maior produção carbonática, tendo como microfácies características packstone a foraminíferos, packstone a briozoários, packstone a braquiópodes e crinoides, packstone a braquiópodes, grainstone bioclástico com braquiópodes, grainstone bioclástico com foraminíferos, grainstone bioclástico oolítico, grainstone peloidal oolítico, grainstone oolítico e grainstone com oóides. Neste trabalho as microfácies packstone com braquiópodes, grainstone com braquiópodes e grainstone com fusulinídeos mostram estreita correspondência com as microfácies relacionadas ao domínio de barras bioclásticas por estes autores.
Quanto às diferenças hidrodinâmicas em porções distintas do domínio de barras bioclásticas, Moutinho (2006) associa as microfácies grainstone bioclástico peloidal a foraminíferos e packstone bioclástico peloidal com porções de energia hidrodinâmica mais baixa, enquanto as microfácies grainstone bioclástico e grainstone oolítico com porções de alta energia. As características destas microfácies são condizentes com as interpretações e diferenciações relacionadas ao índice de energia do meio dentro do domínio de barras bioclástica feitas neste trabalho.

Assim, com base nas correlações acima descritas, este trabalho corrobora o modelo deposicional deplataforma carbonática em rampa sugerido por estes autores. Além disso, infere-se, para a área estudada, o desenvolvimento de um sistema deposicional marinho raso, dominado por sedimentação carbonática, influenciado por maré, sob regime climático dominante de clima semiárido e temperatura da massa d'água variando de temperada a quente (Fig. 5).

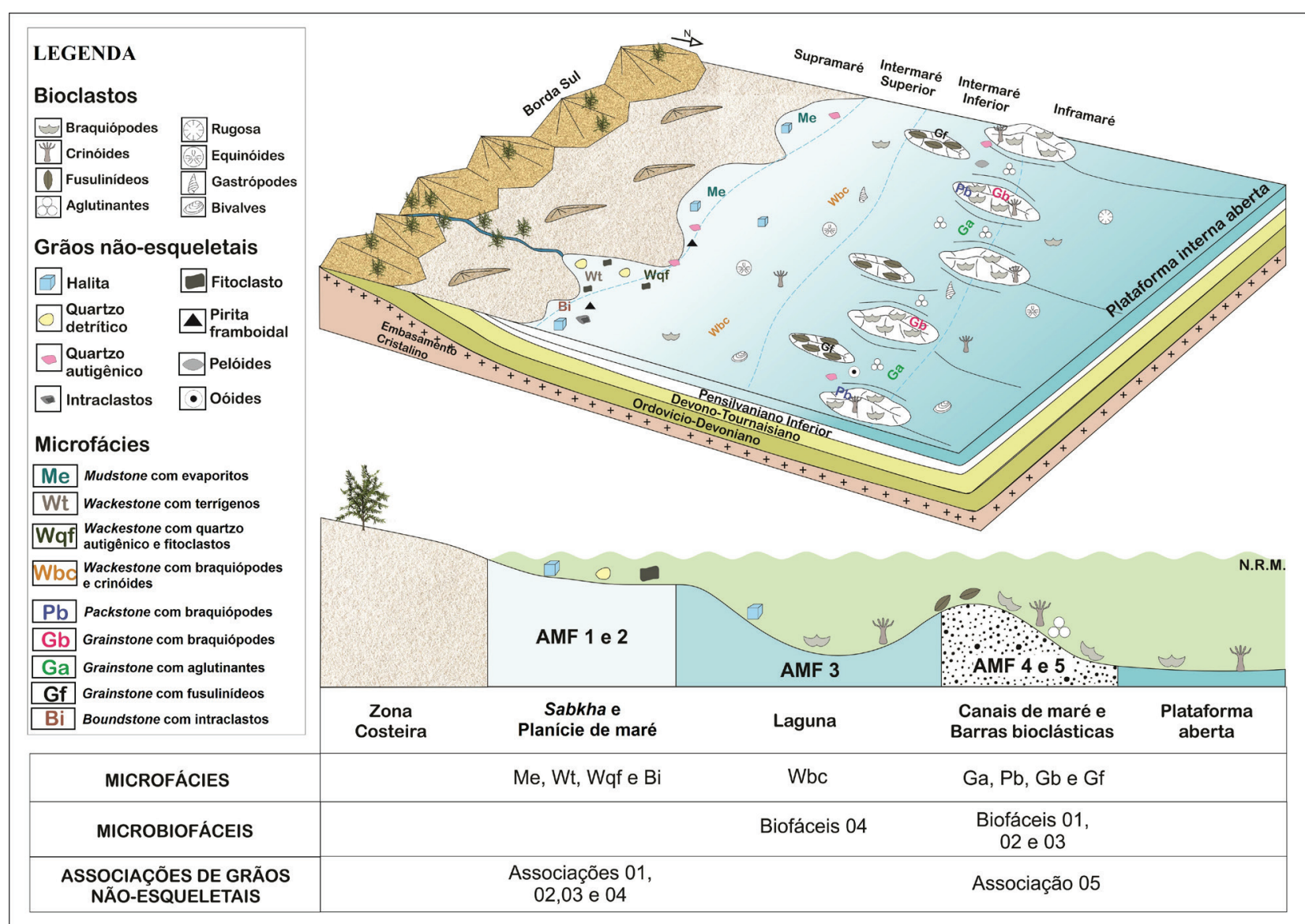

Figura 5. Modelo paleoambiental das seções estudadas baseado nas associações de microfácies. Figure 5. Paleoenvironmental model of the sections studied based on the associations of microfacies. 


\section{Conclusões}

Os resultados petrográficos obtidos exibem estreita correlação com o citado na literatura sobre a caracterização litofaciológica da Formação Itaituba e, consequentemente, corroboram seu significado paleoambiental, interpretado como clara evidência para a instalação de condições francamente marinhas sob um regime climático semi-árido na Bacia do Amazonas durante o Pensilvaniano.

Nesse sentido, o registro de diferentes litotipos, microfácies, microbiofácies, associações de grãos não esqueletais e índices hidrodinâmicos, igualmente demonstra correlação com a ideia de um ambiente marinho nerítico no qual se distinguem vários sistemas deposicionais.

Isso porquê, entre outros fatores, aspectos como o rico conteúdo paleontológico, no qual distingue-se a dominância de formas exclusivamente marinhas (e. g., braquiópodes, crinoides, corais e vários grupos de foraminíferos bentônicos) torna incontestável a natureza marinhada sedimentação,comotambématestam a existência de diferentes paleoecossistemas marinho-costeiros, uma vezquesão reconhecidas diferentes paleocomunidades bióticas, como demonstram as microbiofácies identificadas.

De forma análoga, considerando o contexto paleogeográfico do continente Gondwana durante o Pensilvaniano, a representativa ocorrência de minerais evaporíticos (e. g., halita e moldes evaporíticos aciculares, possivelmente de anidrita), cuja gênese é comumente associada a dessecação e restrições nos padrões de circulação de mares, particularmente mares epicontinentais, corrobora a hipótese de um regime climático semiárido durante a sedimentação da Formação Itaituba. Aspecto que também é suportado pela ocorrência associada de quartzo autigênico, cuja gênese pode estar relacionada ao input fluvial de soluções de intemperismo continental em climas semiáridos, conforme sugere a literatura.

Além disso, estruturas, componentes e aspectos texturais das rochas que compõem a sucessão estudada corroboram a hipótese de uma sedimentação dominada por correntes de maré em um contexto de plataforma carbonática em rampa, como sugerem diferentes autores. Exemplos são a ocorrência, com representativos padrões de frequência e abundância, de pelóides e oncólitos, cuja formação e ocorrência associada são citados como indicativos deste cenário.

Assim, considerando os resultados obtidos e as correlações estabelecidas, propõese para a área estudada um modelo deposicional de plataforma carbonática em rampa (como já sugerido por outros autores para áreas adjacentes investigadas), sob regime climático semiárido e domínio de sedimentação carbonática influenciada por maré, no qual distinguem-se cinco sistemas deposicionais marinho neríticos: sabkha costeira, planície de maré, laguna semirestrita, canais de maré e barras bioclásticas.

Agradecimentos. Agradecemos à CAPES pelo incentivo financeiro, o qual possibilitou a realização deste trabalho. Ao Laboratório de Sedimentologia e Estratigrafia da Petrobrás, Unidade de Manaus (UO/AM), pela confecção das lâminas petrográficas.

\section{Referências}

Ahr, W.M. 1973. The carbonate ramp: an alternative to the shelf model. Transactions: Gulf Coast Association of Geological Societies, 23: 221-225.

Aquilano, D., Otálora, F., Pastero, L. \& GarcíaRuiz, J.M. 2016. Three study cases of growth morphology in minerals: Halite, calcite and gypsum. Progress in Crystal Growth and Characterization of Materials, 62: 227-251.

BouDagher-Fadel, M.K. 2008. Evolution and geological significance of larger benthic foraminifera. Amsterdam, Elsevier, 571p.

Boyer, D.L. \& Droser, M.L. 2009. Palaeoecological patterns within the dysaerobic biofacies: Examples from Devonian black shales of New York state. Palaeogeography, Palaeoclimatology, Palaeoecology, 276: 206216.

Braga, J.C., Fernández-Martínez, E., GarciaBellido, D., Méndez-Bedia, I., MorenoEiris, E., Perejón, A., Rodríguez, S. \& Soto, F. 2009. Poríferos e cnidários. In: Chacón, 
M.L.M. \& Rivas, P. (Eds.). Paleontologia de Invertebrados. Ovideo, Sociedad Española de Paleontología, Instituto Geológico y Minero de España, Universidad de Oviedo e Universidad de Granada, p. 34-107.

Burchette, T.P. \& Wright, V.P. 1992. Carbonate ramp depositional systems. Sedimentary Geology, 79: 3-57.

Caputo, M.V. 1984. Stratigraphy, tectonics, paleoclimatology and paleogeography of northern basins of Brazil. Santa Bárbara, Califórnia (EUA), 586p. Tese de Doutorado, Programa de Pós-Graduação em Geologia, Departamento de Ciências da Terra, Universidade da Califórnia.

Carozzi,A.V.,Alves, R.J \&Castro, J.C. 1972. Controle tectônico sinsedimentar dos carbonatos permocarboníferos das Formações Itaituba e Nova Olinda da Bacia do Amazonas, Brasil. In: CONGRESSO BRASILEIRO DE GEOLOGIA, 26, 1972, Belém. Anais... Belém, SBG, v.3, p. 47-64.

Clark, S.H.B. \& Mosier, E.L. 1989. Barita nodules in Devonian shale and mudstone of western Virginia. U.S. Geological Survey Bulletin, 1880: 30p.

Clarkson, E.N.K. 2007. Invertebrate palaeontology and evolution. Oxford, Blackwell Science, 452p.

CPRM. Serviço Geológico do Brasil. 2010. Geodiversidade do Estado do Amazonas: Programa de Geologia do Brasil, Levantamento da Geodiversidade. Manaus, CPRM, 282p.

CPRM. Serviço Geológico do Brasil. 2016. GEOBANK - Download de arquivos vetoriais. Disponível em: <http://geobank.cprm.gov. $\mathrm{br} />$. Acesso em: 23 de fevereiro de 2016.

Cunha, P.R.C. 2000. Análise estratigráfica dos sedimentos eo-mesodevonianos da porção ocidental da Bacia do Amazonas sob a ótica da estratigrafia de sequências no interior cratônico. Porto Alegre, 263 p. Dissertação de Mestrado, Programa de Pós-Graduação em Geociências, Instituto de Geociências, Universidade Federal do Rio Grande do Sul.

Cunha, P.R., Melo, J.H.G. \& Silva, O.B. 2007. Bacia do Amazonas. Boletim de Geociências da Petrobrás, 15(2): 227-251.

Dunham, R.J. 1962. Classification of carbonate rocks according to depositional texture. In: Ham, W.E. (Ed.). Classification of carbonate rocks. Tulsa, American Association of Petroleum Geologists, Memoir 1, p. 108-122.

Figueiras, A.J.M. 1983. Petrologia dos carbonatos da Formação Itaituba, na região de AveiroPA. Belém, 135p. Dissertação de Mestrado, Programa de Pós-Graduação em Geociências, Instituto de Geociências, Universidade Federal do Pará.

Flügel, E. 2010. Microfaceis of carbonate rocks. Analysis, Interpretation and Application. Berlin, Springer, 996p.

Gainey Jr., L.F. \& Greenberg, M.J. 1997. Physiological Basis of the Species Abundance- Salinity Relationship in Molluscs: A Speculation. Marine Biology, 40(1): 41-49.

Gili, C. \& Martinell, J. 2009. Clase gastropoda In: Chacón, M.L.M. \& Rivas, P. (Eds.). Paleontologia de Invertebrados. Ovideo, Sociedad Española de Paleontología, Instituto Geológico y Minero de España, Universidad de Oviedo e Universidad de Granada, p. 271-300.

Hasui, Y., Carneiro, C.D.R., Almeida, F.F.M. \& Bartorelli, A. 2012. Geologia do Brasil. São Paulo, Editora Beca, 900p.

Irwin, M.L. 1965. General theory of epeiric clear water sedimentation. American Association of Petroleum Geologists Bulletin, 49: 445-459.

Klemm, E.B., Reed, S.A., Pottenger III, F.M., Porter, C. \& Speitel, T.W. 2008. The living ocean:Biology and technology of the marine environment. Honolulu, University of Hawai'i, 451p.

Kültz, D. 2015. Physiological mechanisms used by fish to cope with salinity stress. Journal of Experimental Biology, 218: 1907-1914.

Lima, H.P. 2010. A sucessão siliclásticacarbonática Neocarbonáfera da Bacia do Amazonas, regiões de Monte Alegre e Itaituba (PA). Belém, 149p. Dissertação de Mestrado, Pós-Graduação em Geologia e Geoquímica, Instituto de Geociências, Universidade Federal do Pará.

Matsuda, N.S. 2002. Carbonate sedimentation cycle and origin of dolomite in the Lower Pensylvanian intracratonic Amazon Basin, Northern Brazil. Tokyo, 223p. Master Thesis, Departament of Earth and Planetary Science, University of Tokyo.

Mendes, M.C.S. 2015. Estudo de Palinofácies e Biomarcadores de uma sondagem realizada 
na região de Alcobaça (Bacia Lusitânica) Porto, 128p. Dissertação de Mestrado, Programa de Pós-Graduação em Geologia, Departamento de Geociências e Ordenamento do Território, Universidade do Porto.

Menezes, T.R. \& Mendonça-Filho, J.G. 2004. Aplicação de fácies orgânica na análise paleoceanográfica do talude continental superior recente da Bacia de Campos, RJ, Brasil. Revista Brasileira de Paleontologia, 7(2): 177-188.

Miall, A.D. 1977. A review of the braided-river depositional environment. Earth-Science Reviews, 13: 1-62.

Milani, E.J. \& Thomaz Filho, A. 2000. Sedimentary Basins of South America. In: Cordani, U.G.; Milani, E.J.; Filho, A.T. \& Campos, D.A. (Eds.). Tectonic Evolution of South America. Rio de Janeiro, 31 International Geological Congress, p. 389-452.

Moutinho, L.P. 2006. Assinaturas tafonômicas dos invertebrados da Formação Itaituba - aplicação como ferramenta de análise estratigráfica e paleoecológica na seção pensilvaniana aflorante na porção sul da Bacia do Amazonas, Brasil. Porto Alegre 325p. Tese de Doutorado, Programa de Pós-Graduação em Geociências, Instituto de Geociências, Universidade Federal do Rio Grande do Sul.

Moutinho, L.P., Nascimento, S., Scomazzon, A.K. \& Lemos, V.B. 2016a. Trilobites, scolecodonts and fish remains occurrence and the deposicitional paleoenvironment of the upper Monte Alegre and lower Itaituba formations, Lower - Middle Pennsylvanian of the Amazonas Basin, Brazil. Journal of South American Earth Sciencies, 72:76-94.

Moutinho, L.P., Scomazzon, A.K., Nascimento, S. \& Lemos, V.B. 2016b. Taphofacies of LowerMiddle Pennsylvanian marine invertebrates from the Monte Alegre and Itaituba formations, part of the outcropped marine sequence of the Tapaj_os Group (Southern Amazonas Basin, Brazil) e regional palaeoecological models. Journal of South American Earth Sciences, 70: 83-114.

Murray, J.W. 1970. The foraminifera of the hypersaline Abu Dhabi Lagoon, Persian Gulf. Lethaia, 3: 51-68.
Nascimento, S., Lemos, V.B., Scomazzon, A.K., Matsuda, N.S. \& Silva, C.P. 2010. First occurrence of Ellisonia, Gondolella and Ubinates (Conodonts) in Itaituba Formation, Pensylvanian of Amazonas Basin, Brazil. Gaea: Journal of Geoscience, 6(2): 56-62.

Neves, M.P. 2009. Petrografia de carbonatos da Formação Itaituba (Carbonífero Superior), Bacia do Amazonas, região de Monte Alegre, PA. Belém, 71p. Monografia de Conclusão de Curso, Curso de Geologia, Instituto de Geociências, Universidade Federal do Pará.

Nichols, G. 2009. Sedimentology and Stratigraphy. Oxford, Wiley-Blackwell, 432p.

Pereira, P.A. 2011. Aspectos taxonômicos e paleoecológicos dos braquiópodes e moluscos (bivalves) da Formação Inajá (Devoniano), Bacia do Jatobá (PE). Recife, 128p. Dissertação de Mestrado, Programa de Pós-Graduação em Geociências, Centro de Tecnologia e Geociências, Universidade Federal de Pernambuco.

Posada, L.C.S., Arbizu, M., Delclòs, X., Gozalo, R., Liñán, E., Peñalver, E., Rábano, I. \& RodríguezLázaro, J. 2009. Artrópodos In: Chacón, M.L.M. \& Rivas, P. (Eds.). Paleontologia de Invertebrados. Ovideo, Sociedad Española de Paleontología, Instituto Geológico y Minero de España, Universidad de Oviedo e Universidad de Granada, p. 111-219.

Read, J.F. 1985. Carbonate platform facies models. American Association of Petroleum Geologists Bulletin, 66: 860-878.

Scholle, P.A. \& Ulmer-Scholle, D.S. 2003. A Color Guide to the Petrography of Carbonate Rocks: Grains, textures, porosity, diagenesis. Oklahoma, AAPG Memoir 77, 470p.

Scomazzon, A.K. \& Lemos, V.B. 2005. Diplognathodus occurrence in the Itaituba Formation, Amazonas Basin, Brazil. Revista Brasileira de Paleontologia, 8(3): 203-208.

Scomazzon, A.K., Moutinho, L.P., Nascimento, S., Lemos, V.B., Matsuda, N.S. 2016. Conodont biostratigraphy and paleoecology of the marine sequence of the Tapajós Group, EarlyMiddle Pennsylvanian of Amazonas Basin, Brazil. Journal of South American Earth Science, 65: 25-42.

Shin, E.A. 1983. Tidal flat environments. In: 
Scholle, P.A., Bebout, D.G. \& Moore, C.H. (Eds.). Carbonate Depositional Environments. Memoir American Association of Petroleum Geologists, 33: 173-210.

Silva, O.B. 1996. Ciclicidade sedimentar no Pensilvaniano da Bacia do Amazonas e o controle dos ciclos de sedimentação na distribuição estratigráfica dos conodontes, fusulinídeos e palinomorfos. Porto Alegre, 331 p. Tese de Doutorado, Programa de PósGraduação em Geociências, Instituto de Geociências, Universidade Federal do Rio Grande do Sul.

Silva, M.A.M., Schreiber, B.C. \& Santos, C.L. 2000. Evaporitos como recursos minerais. Brazilian Journal of Geophysics, 18(3): 337-350.

Silva, P.A.S. 2014. Paleoambiente e diagênese da Formação Itaituba, Carbonífero da Bacia do Amazonas, com base em testemunho de sondagem, região de Uruará, Pará. Belém, 91p. Dissertação de Mestrado, Programa de Pós-Graduação em Geociências, Instituto de Geociências, Universidade Federal do Pará.

Silva, P.A.S., Afonso, J.W.L., Soares, J.L. \& Nogueira, A.C.R. 2015. Depósitos de plataforma mista, Neocarbonífero da Bacia do Amazonas, região de Uruará, estado do Pará. Geologia USP Série Científica, 15(2): 79-98.

Souza, E.S. 2016. Microfácies e interpretação paleoambiental dos carbonatos da Formação Itaituba (Grupo Tapajós) na região do Município de Itaituba - PA. Manaus, 51p. Monografia de Conclusão de Curso, Curso de Geologia, Departamento de Geociências, Universidade Federal do Amazonas.

Suits, N.S. \& Wilkin, R.T. 1998. Pyrite formation in the water column and sediments of a meromictic lake. Geology, 26(12): 1099-1102.

Teixeira, V.M. 2017. Microfácies carbonáticas da Formação Itaituba (Grupo Tapajós, Bacia do Amazonas) na região do Rio Jatapú, AM. Manaus, 49p. Monografia de Conclusão de Curso, Curso de Geologia, Departamento de Geociências, Universidade Federal do Amazonas.
Villalba, M.P. 2009. Clase Echinoidea. In: Chacón, M.L.M. \& Rivas, P. (Eds.). Paleontologia de Invertebrados. Ovideo, Sociedad Española de Paleontología, Instituto Geológico y Minero de España, Universidad de Oviedo e Universidad de Granada, p. 447-496.

Wightman, W.G., Scott, D.B., Medioli, F.S. \& Gibling, M.R. 1994. Agglutinated foraminifera and thecamoebians from the Late Carboniferous Sydney coalfield, Nova Scotia: paleoecology, paleoenvironments and paleogeographical implications. Palaeogeography, Palaeoclimatology, Palaeoecology, 106: 187202. 